\title{
DIFFERENT INSTITUTIONAL ARRANGEMENTS FOR JOB PLACEMENT
}

\author{
Friedrich Buttler and Ulrich Walwei
}

\section{INTRODUCTION}

In several European countries (e.g. Belgium, France, and Norway) public employment services still have a monopoly position. In contrast to this, in other countries (e.g. the United States, the United Kingdom, and Swizzerland) public employment services (PES) and private employment services (PRES) have now been coexisting for quite some time. Recently a tendency toward liberalization in the area of job placement has been observed. In Denmark, Germany, the Netherlands, and Sweden public employment services have lost their monopoly position. Different institutional arrangements for job placement in Europe have also given rise to to changes within the framework of the Single European Market. It is questionable whether the prohibition of market entry for private employment services is reconcilable with the freedom to provide services guaranteed in the EEC treaties.

During the 1970's and 1980's private employment services that intervene in the functioning of labor markets exerted a growing influence. Such agencies cover a wide range of activities, for example, fee-charging employment agencies, management consultants, outplacement agencies, temporary work agencies, and self-help associations (ILO 1994). There are several reasons of the sector's growth and employers' motives for delegating to others the tasks of selecting or recruiting the staff they need (Caire 1991). The growth of the business is linked to the employers' discovery of the importance of human resources, as well as to the policy of externalizing a certain number of functions, so that the firm can concentrate on its own speciality.

The main purpose of this chapter is to assess the effects of different regulatory regimes (placement monopoly versus coexistence) on the functioning of the labor market by using a transnational analysis. In particular we will comment on two interesting findings of a recent OECD review report on PES. Their data on hirings suggest on the one hand that the monopoly status of the PES may not necessarily improve its market share (OECD 1992: 122). On the other hand, the report states that the existence of PRES does not preclude a comparatively high market share of the PES (1992: 141). These findings require an explanation. The chapter starts 
with theoretical considerations on the role of employment services as brokers in the labor market. Subsequently, different institutional arrangements for job placement are discussed by comparing regulations and appropriate empirical findings internationally. Finally, the chapter examines the need for institutional changes and innovations in the area of job placement.

\section{FUNCTIONS AND IMPACT OF JOB PLACEMENT}

\section{Increasing Transparency}

Markets are generally speaking not transparent. It is uncertain where one can obtain something, or offer something, what price must be paid or what price can be obtained, and what kind of quality the exchanged object has. This lack of transparency can be reduced by gathering information. Information, however, is not given free of charge. Gathering information costs time and money, and information will usually cost more the more quickly it is required. The fact that information costs money makes it necessary to have certain mechanisms or institutions to be able to carry out an efficient exchange (Akerlof 1970: 488). Examples of this are newspaper advertisements, informal contacts, or agents. Agents can be brought in if it is possible for them to increase the net return of information for the exchange partners by increasing the gross return or reducing the cost of the transaction (compared with the cost and gross returns of using alternative channels of information).

These theoretical considerations are especially relevant to the labor market. Labor markets are not at all homogeneous. Jobs and skills differ greatly. In addition, personal attitudes on both sides play an important role. Therefore matching vacant jobs and persons looking for employment is a difficult, complex and cost-intensive task. Employers and workers will be ready to use job placement agencies if the expected net return of using them is higher as compared with other search channels. An optimum filling of vacancies demands extensive knowledge of companies' skill needs on the one hand, together with the suitability of the employees on the other hand. Only where job agents have expert knowledge of specific parts of the labor market can they expect to be brought into the search process.

But due to certain peculiarities of the labor market it is difficult to judge the usefulness of using external placement agents. The quality of jobs and the performance of workers are experience goods (Spence 1973: 355). This wellknown fact leads to the conclusion that the actual benefit of using job placement agents could not be determined on completion of the contract. Therefore, job placement services themselves are an experience good. For this reason the reputation of a placement agency will be of significant importance for its success in the future, i.e. the possibility of being brought into the search process is mainly dependent on the quality of that service in the past.

It must also be mentioned that hiring expenditure includes the cost of search and selection. The cost of search and the cost of selection could be interdependent. 


\section{FRIEDRICH BUTTLER, ULRICH WALWEI}

Search activities based on specified and well-defined criteria entail the higher cost of finding suitable candidates but the lower cost of selection and vice versa. In both cases placement agencies could have a certain task. In one case they support predominantly search activities by finding suitable candidates, in the other mainly the effectiveness of selection decisions. Job brokers can therefore either be search and/or selection agents (which is the case e.g. as PRES activities show).

\section{Employment Effects}

PES or PRES will in general only be used if they are cost-effective. This statement can be illustrated by a simple hypothetical example. Suppose a firm has to fill a vacancy and can use either PES or PRES instead of or in addition to its own search activities. Relevant for the decision whether or whether not to use a placement service are:

- the benefit $(B)$ of searching which is the expected productivity of the selected worker;

- the cost $(C)$ of searching which includes the cost of using external agencies $\left(C_{\text {ext. }}\right)$, of handling the job filling internally $\left(C_{i n t}\right)$ and of not filling or unsatisfactorily filling the vacancy $\left(C_{\text {rac. }}\right)$

An efficient firm will only commission any kind of employment service if the resulting additional benefits are higher than the additional cost of hiring:

$$
(B)>\left(C_{\text {rxt. }}+C_{i n t}+C_{\text {rac. }}\right)
$$

This means, the use of an employment service will be more likely

- if, ceteris paribus, the recruited worker is expected to be more productive $(+B)$, and/or

- if, ceteris paribus, the cost of handling the job filling internally can be reduced by contracting this task out to outside agencies $\left(-C_{i n t}\right)$, and/or

- if, ceteris paribus, the vacancy can be filled more quickly and adequately $\left(-C_{r a c}\right)$.

Due to the fact that a fee is charged for the use of a PRES, whereas a PES is free of charge, it would only make sense for the firm to commission the PRES if its use results in additional benefits or additional cost savings. Therefore, these theoretical reflections suggest that the market potential for PES is in general the more difficult job fillings in terms of qualification requirements. The advantages of a PRES can either be its deeper knowledge of certain segments of the labor market or better knowhow and more resources to select suitable candidates. Similar theoretical considerations with quite similar suggestions are possible from the viewpoint of the job seeker. In general, public job placement officers as well as private job placement agents could make the matching of labor and vacancies easier and improve the 


\section{DIFFERENT INSTITUTIONAL ARRANGEMENTS FOR JOB PLACEMENT}

functioning of the labor market. In addition those services potentially increase employment and consequently reduce unemployment. These hypotheses can be clarified by some further theoretical reflections.

The level of unemployment or more precisely the unemployment rate is the result of two different effects: On the one hand, the inflow of the labor force to unemployed status (i.e. the risk of becoming unemployed) and on the other hand, the average duration of unemployment between the date of registration and the date of being taken off the unemployment register (i.e. the risk of staying in the unemployed status). The UR-curve in Figure 10.1 represents combinations of inflow rate and duration figures which lead to the same unemployment level. It shows that the level of unemployment could be reduced either by a decrease of the inflow rate or by a decrease of the average duration of the spells of unemployment.

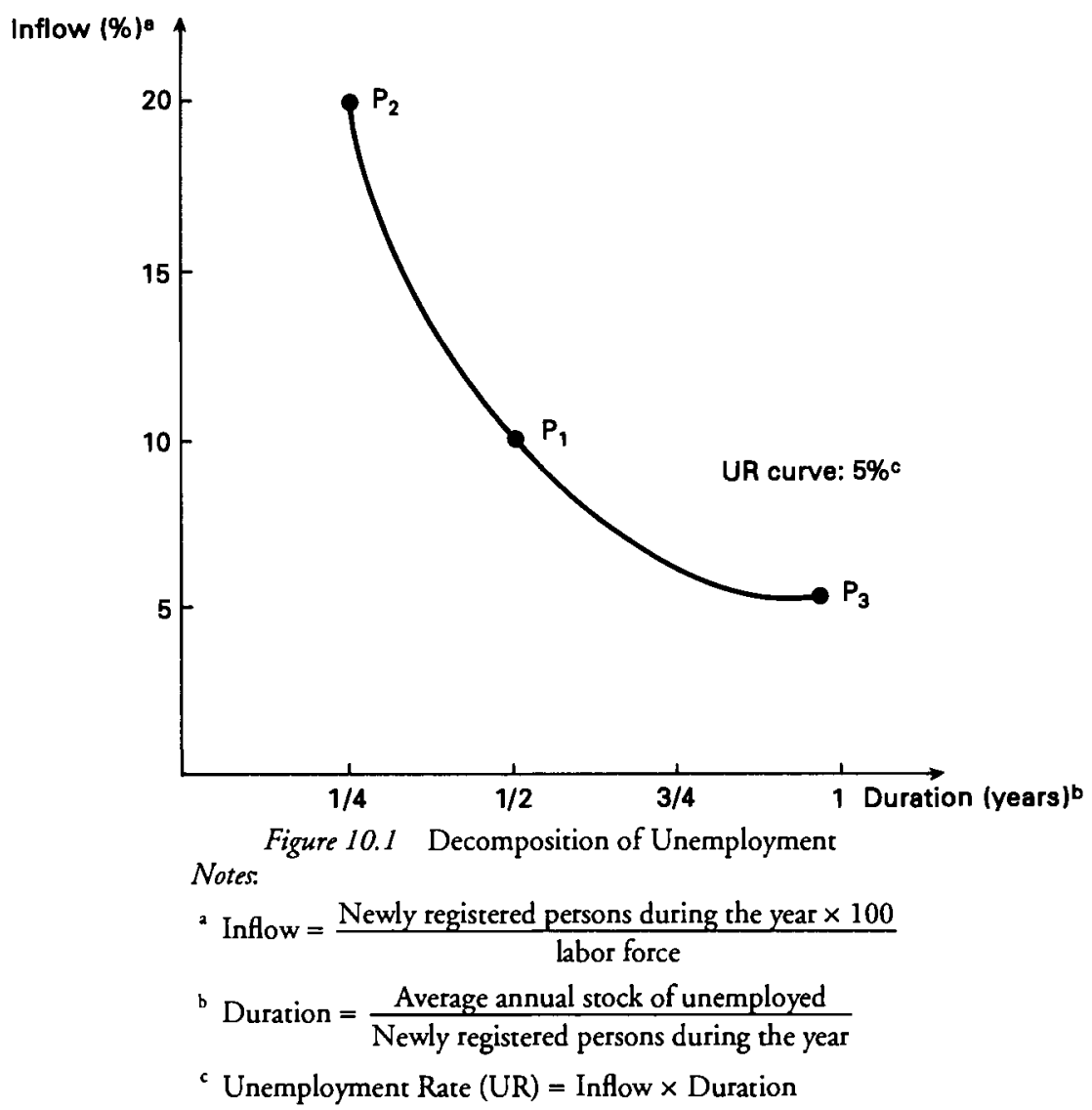


In both cases a downward shift of the curve will be the result. The UR-curve also shows that a movement leftwards along the curve would mean an improvement in the unemployment composition. With respect to labor market policy considerations it would be better to have a certain unemployment rate with a low duration value and a comparatively high inflow rate instead of a low inflow rate but a high duration value (as it is unfortunately the case in many OECD countries). Job placement influences the inflow rate, the duration value and the unemployment composition.

By supporting the marching process, efficient job placement contribures to a longer average duration of employment periods. They help to place workers in the job where they can be used most productively. In consequence, mismatch will be less likely and the risk of becoming unemployed (due to a mismatch) will be reduced. An improvement in the job matching process through placement agents can also be illustrated by the Beveridge Curve. It displays the theoretical relationship between the stock of unfilled vacancies and the stock of unemployed. The further "outside" the curve is situated the more acure are mismatch problems. A shift of the curve to the left implies an easier matching of labor supply and demand due e.g. to more transparency and better information on the labor market. One reason for a leftward shift of the Beveridge Curve could be-other things being equal - more efficient employment services.

An improvement of the matching process would not only mean better matching but also quicker matching. Efficient employment services would reduce the duration of vacancies to a certain unavoidable minimum. A shorter duration of vacancies would tend to increase the number of employed and reduce the average duration of unemployment (especially frictional unemployment). But this effect should not be overestımated. A shorter duration of vacancies (e.g. due to efficiently working employment services) must not necessarily lead to the corresponding increase in employment. The effect could be smaller because firms are in competition with one another. The expansion in one firm due to a (quicker) filling of vacancies could result in job losses and in the cancelling of vacancies in other firms (Reyher et al. 1990). In addition the possible effect on the duration of vacancies might be comparatively small because speedy and tailor-made filling of a vacancy is difficult to achieve at the same time and could thus be contradictory. Tailor-made filling takes time because the company's skill needs and the applicants' qualifications must be harmonised with one another as far as possible.

Efficiency of employment services means optimum matching of vacancies with persons looking for employment. Although their effects on the quality of the matching process and the level of unemployment are clear-cur and positive, the effects on the unemployment composition need further consideration. Because efficiently operating services concentrate on the most promising job seeker when acquiring applicants, this could lead to an even greater segmentation of the labor market. Special and more intensive help and advice would then be necessary and could enable (long-term) unemployed to move into employment. Especially in order to combat and prevent long-term unemployment (LTU) and its negative 
long-term consequences (such as the devaluation of human capital) active labor marker policies play an important role. Therefore, the combination of those policies (e.g. wage cost subsidies for target and problem groups of the labor market) with effective placement could be a powerful instrument to foster the reintegration of (long-term) unemployed people in the labor market. Help to the LTU and other disadvantaged unemployed people produces greater benefits to the economy in terms of lower benefit payments and higher tax flowbacks. But attention must be paid to the fact that there are increasing marginal costs of reintegrating long-term unemployed. That is caused by diminishing marginal returns of reintegration policies. The more long-term unemployed are covered by reintegration policies, the more we are confronted with the hard core of this group. The more we are confronted with the hard-to-place people, the more we need assisted matching and support by social workers.

\section{INTERNATIONAL COMPARISON OF JOB PLACEMENT}

\section{Legal Framework}

Looking to the situation in different countries as far as the role of public employment services and the admittance of their private counterparts is concerned, we can see varying conditions from one country to another (cf. Table 10.1). The following international comparison includes the United States, Japan and several European countries (Walwei 1991). There are public employment services in all the countries in the survey which carry out job placement free of charge and which are financed by public funds. Apart from the two extreme forms of a more or less strict PES monopoly and the coexistence of public and private institutions, varying situations can also be found between the two extremes.

There is a relatively strict PES monopoly in Greece, Italy, and Spain. In these countries fee-charging private employment services are not allowed at all and there is an obligation for firms to norify the PES of any vacancies. However, the illegal (placement) activities of management consultants and other agents (such as temporary work agencies) are often tolerated to a great extent.

In contrast to this there is a coexistence between public employment services and fee-charging private services in Denmark (since July 1990), Germany (since August 1994), the United Kingdom, Ireland, Portugal, the Netherlands (since January 1991), the United States, Sweden (since July 1993), and Switzerland. In Denmark, Sweden, and the United States PRES can carry on business without a special license. Just like any other company, such agencies acquire their legitimacy by being entered on the commercial register and by declaring themselves to the tax authorities. In the United States there is no federal law that specifies what a PRES is allowed to do. Instead, prohibited actions are defined; e.g. according to the Civil Rights Act of 1964 private (as well as public) placement agencies have to provide services without regard to race, color, sex, or national origin. In addition to that, nearly all states have enacted their own laws regulating PRES activities. For some 


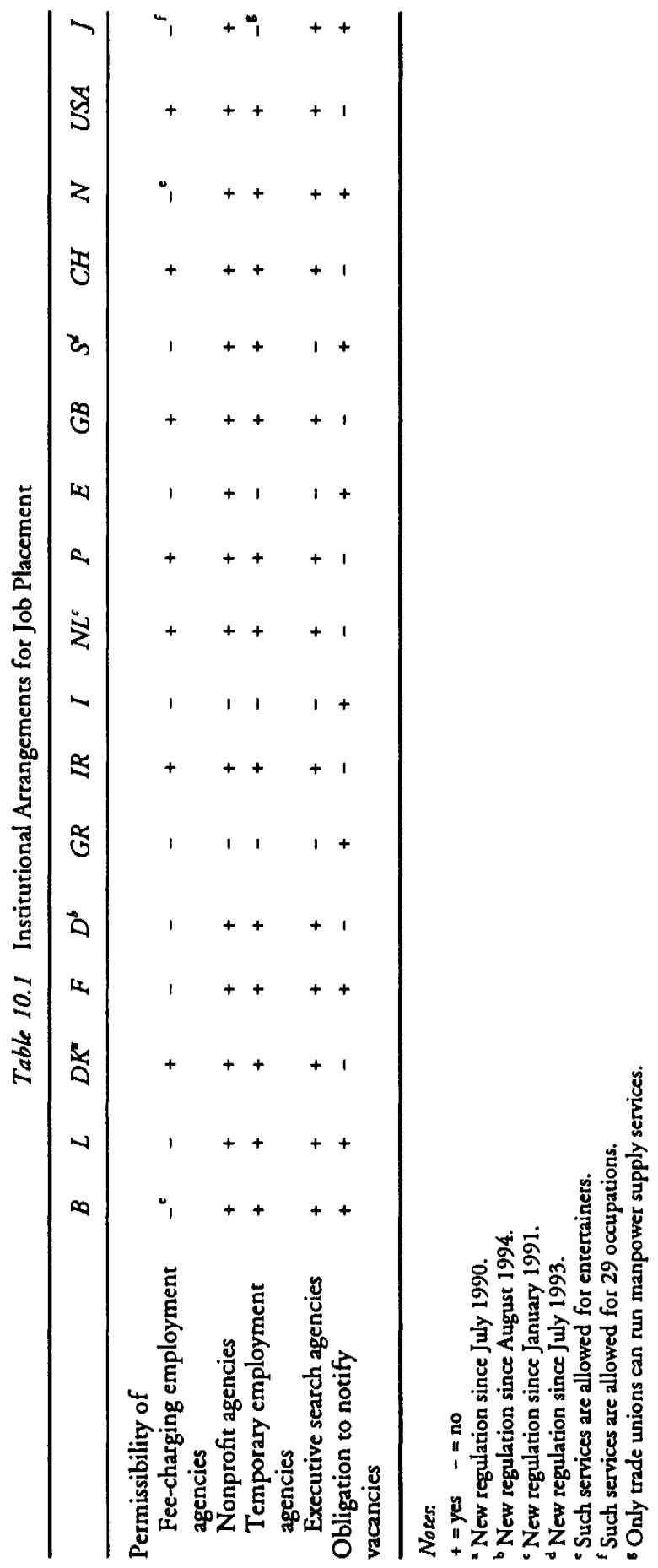


states, only registration is required. In other states, regulatory laws are applicable and contain some prohibited practices (e.g. false advertisement or referring candidates to establishments where a strike or lockout is in force). But in general, in the United States regulation of PRES can be judged as quite liberal (Stevens 1989: 10).

In contrast, private employment services in the other coexistence countries mentioned only have the legal right to run an agency if a supervisory authority (generally the employment service) judges that the applicant meets certain criteria. For example, in the United Kingdom a PRES needs a current license from the Secretary of State for Employment. A license may be refused or revoked on the grounds that: The applicant is under twenty-one years of age; the applicant is unsuitable because of misconduct; the premises are unsuitable. In addition certain regulations set the standards of service to be provided (e.g. with regard to advertisements, fees, young people under eighteen or employment abroad). According to the new Swiss Placement Code (July 1991) every PRES (including executive search) has to apply for a license. This PRES regulation is intended to protect jobseekers from abusive methods and also constitute a uniform federal basis throughout the Swiss Federation.

Many coexistence countries regulate the charging of fees. In the United Kingdom, Ireland, the Netherlands, Germany, and Sweden, placement fees may be demanded from the employers only (except the finding of jobs for workers in the entertainment field). In contrast to that, in Switzerland the registration fee payable by the clients to the licensed placement firms is limited to a very low sum. The Swiss Employment Code provides that the fee must not exceed 12 percent of the first month's salary, the employees may pay only up to 6 percent of their first salary. Expenses are usually not included in the fee payable and can be charged separately. A peculiarity of the Swiss and German systems is that a PRES must publish statistics concerning the number of jobseekers registered or placed, vacancies received or filled, and placements made. A special feature of the Swedish placement system is that-although PRES are not forbidden anymore-companies are obliged to notify all vacancies to the PES.

In the other countries, the placement systems lie between the two extremes. In Belgium the PES is the sole body responsible for job placement. Only in exceptional cases does the PES entrust a commercial PRES with job placement for individual occupations or for groups of persons (especially in the case of entertainers and executives). In addition, job placement may be carried out free of charge by various private agencies (e.g. educational institutions) to complement the state placement service. In Luxembourg a commercial PRES must restrict itself to recruiting workers abroad. In Japan PRES are in principle prohibited. However, such services may be operated in 29 occupations requiring special technical skills in which the PES alone may not fully meet supply and demand (e.g. engineers, dentists). In France, apart from the PES, only institutions (e.g. chambers of commerce, universities) - whether private or public - which work free of charge 
may place workers in employment. In addition, a restricted number of commercial private employment services are allowed under certain circumstances. In Norway (as in Sweden) companies are obliged to notify the PES of all vacancies. Since 1993 there have been no restrictions on commercial placement of executives and entertainers.

The commercial supply of workers by temporary employment agencies can be regarded partly as a substitute for commercial job placement (cf. Konle-Seidl et al. 1990). The main difference between a contract to supply workers on a temporary basis and the regular placement service is that the legal relationship between the agency and the temporary worker outlasts the individual temporary job, but that the individual job is not aimed at establishing a new employment contract. However, the hired temporary workers can be candidates for the firms employing them in their search for employees on a permanent basis. Temporary work agencies are not permitted at all in Greece, Italy, and Spain. There are no substantial restrictions (with the exception of the duty to obtain a license) on the supply of temporary employment in Denmark, Great Britain, Ireland, Luxembourg, Portugal, and the United States. Fee-charging employment agencies in Great Britain, Denmark, Ireland, and the United States may also supply temporary workers. In Belgium, the Netherlands, France, Germany, and Japan a limited permissibility can be spoken of (e.g. a limit on the length of time for temporary work or the exclusion of certain sectors of industry).

\section{Public Employment Services}

The OECD report on public employment services already quored gives an interesting and illustrating picture of the tasks assigned to them, their resources and market importance. The main findings of this report (which includes Norway, Spain, the United Kingdom, and Japan) with special respect to job placement will be summarized in this chapter and be supplemented by information and data on the situation in the Netherlands, Germany, and the United States (OECD 1993; Bundesanstalt für Arbeit 1992; National Commission for Employment Policy 1991).

In all the countries under review, the PES is responsible for, besides the provision of job placement services, most aspects of the administration of unemployment insurance benefits. In addition they are, to varying degrees, responsible for the implementation of certain labor market measures (e.g. jobsearch help, guidance on places on training and job-creation schemes). Not surprisingly the bulk of PES staff is located in local offices. In all countries under review, a substantial proportion of PES staff is still devoted to benefit administration, as opposed to active labor market policies (including placement). In the United Kingdom, benefit administration occupies over 60 percent of staff resources. In western Germany, only about 25 percent of staff resources in local offices is devoted to job placement and counseling.

To facilitate the matching process the PES in the countries under review codify a range of variables (e.g. occupation, salary offered or sought, and age). In practice, 
much job placement occurs in local labor markets that have a limited range of vacancies which are in general notified by telephone. Most commonly, vacancy information is shown either on cards or on a display screen in local offices. Matching is still mainly done by PES placement officers who propose a candidate after receiving a job offer. To complement this many PES have recently established self-service systems. In the British "semi-open" self-service system, card displays show only basic information (occupation, salary, and working hours). For further details the jobseeker must approach a placement officer, especially in order to get the address and telephone number. Quite similar to the British system is the American "Interstate Job Bank" (IJB). Job openings are usually available on microfiche, but may also be available on computer terminal screen. But the IJB is, like the British card system, a semi-open self-service system because a referral to a job listed on the IJB can only be made by PES staff. In the "fully open" system, or open-file system, in Norway and Japan all the relevant information is available on screen without the need for a placement officer to be contacted. In Germany, a similar computer system has recently been established in nearly all local PES.

There are two main indicators of the market share of PES activities with respect to placement: The proportion of registered vacancies and the proportion of all hirings that are made with PES support. Table 10.2 shows the relevant figures for the review countries. The relatively low percentage of placements as a percentage of vacancy notifications and of all hirings in Norway and Japan is to some extent due to the "fully-open" systems in both countries. It is difficult to count self-service transactions. Therefore, in those countries the proportion of registered vacancies (as a measure of the intended use of the PES) is getting more important. The PES in the U.S. obviously has the lowest market share of all countries in the survey. But attention must be paid to the fact that the placement ratio varies considerably from one state to another (see Table 10.3). The placement ratios listed in both tables are comparable to a limited extent only because of the different methods used to record the statistics in each country. In addition the number of placements in a given period reflects neither the effort made by the PES nor the value of each placement (see OECD 1984 and page 260).

In spite of these difficulties the comparison does allow careful conclusions to be drawn. As the figures show, most vacancies are filled without the intervention of the PES. In countries in which PES and PRES coexist one can find a controversial picture. Whereas the market share of the PES (as a percentage of all hirings) in the United States is much lower than in those countries with a placement monopoly (e.g. Spain and Germany, where PES were forbidden until 1994), the British PES has been able to defend its position much better. Therefore, looking to the situation in the UK one can argue (as the OECD report does) that the coexistence of public and private placement services does not necessarily lead to a comparatively low market importance of the PES. But looking to other "monopoly" countries (e.g. such as France, with a market share for the PES of 12 percent) it can also be stated that a placement monopoly does not necessarily lead to a comparatively high market share. 


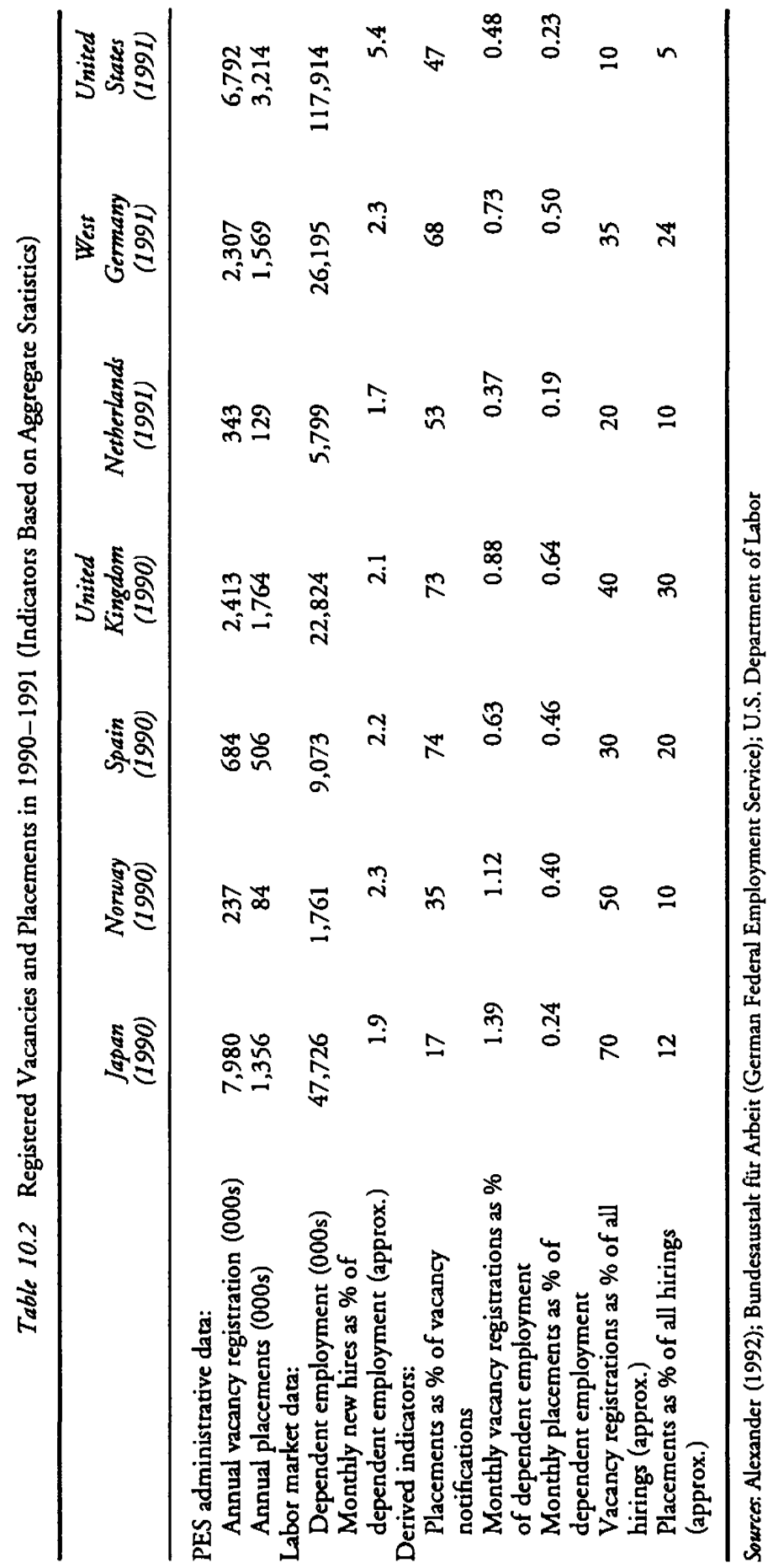


Table 10.3 Market Share of the U.S. Employment Service (1990) - Selected States with Comparatively High or Low Market Shares

\begin{tabular}{lc}
\hline State & Market Share (\%) \\
\hline South Dakota & 28.1 \\
North Dakota & 21.1 \\
Alaska & 20.7 \\
Idaho & 17.9 \\
Wyoming & 16.2 \\
& \\
U.S. Total & 4.8 \\
& \\
Rhode Island & 1.8 \\
Connecticut & 1.8 \\
Massachusetts & 1.7 \\
Delaware & 1.2 \\
New Jersey & 1.0 \\
\hline
\end{tabular}

Source: U.S. Department of Labor

In addition to the total share of PES placements and registered vacancies it is important what kind of jobs and workers they are dealing with. A tentative answer can be given by data from the United Kingdom as a "coexistence country" and Germany (as a "former monopoly country"). Table 10.4 illustrates the market importance of the British PES subdivided into different segments. Employers were more likely to contact job centers when recruiting skilled manual or unskilled staff. On the other hand job seekers who use job centers tend to be unemployed, are more likely to work in a manual profession, to live in rural regions, and to have comparatively low skills (Harrison 1991). This statement is in general also true for Germany. A company survey shows that the proportion of registered vacancies (related to total vacancies) is the lower the higher the skill requirements are (Reyher et al. 1990).

The PES are in general more concerned with the supply side of the labor market because their main objective is, of course, to place unemployed people. In particular they need to help those unemployed who are less attractive to employers (e.g. the long-term unemployed). By doing this their reputation with employers may suffer. Consequently, in many countries, the main complaint of employers about the PES is that it does not supply suitable candidates. That is not only because of an-as often criticized-insufficient preselection of candidates, but also due to a considerable lack of qualified candidates. That means the stigma of PES candidates can stigmatize PES itself. This signaling argument suggests that PES might not concentrate its placement activities only on hard-to-place people. If they lose their middle-class constituency they will be in danger of being driven out 


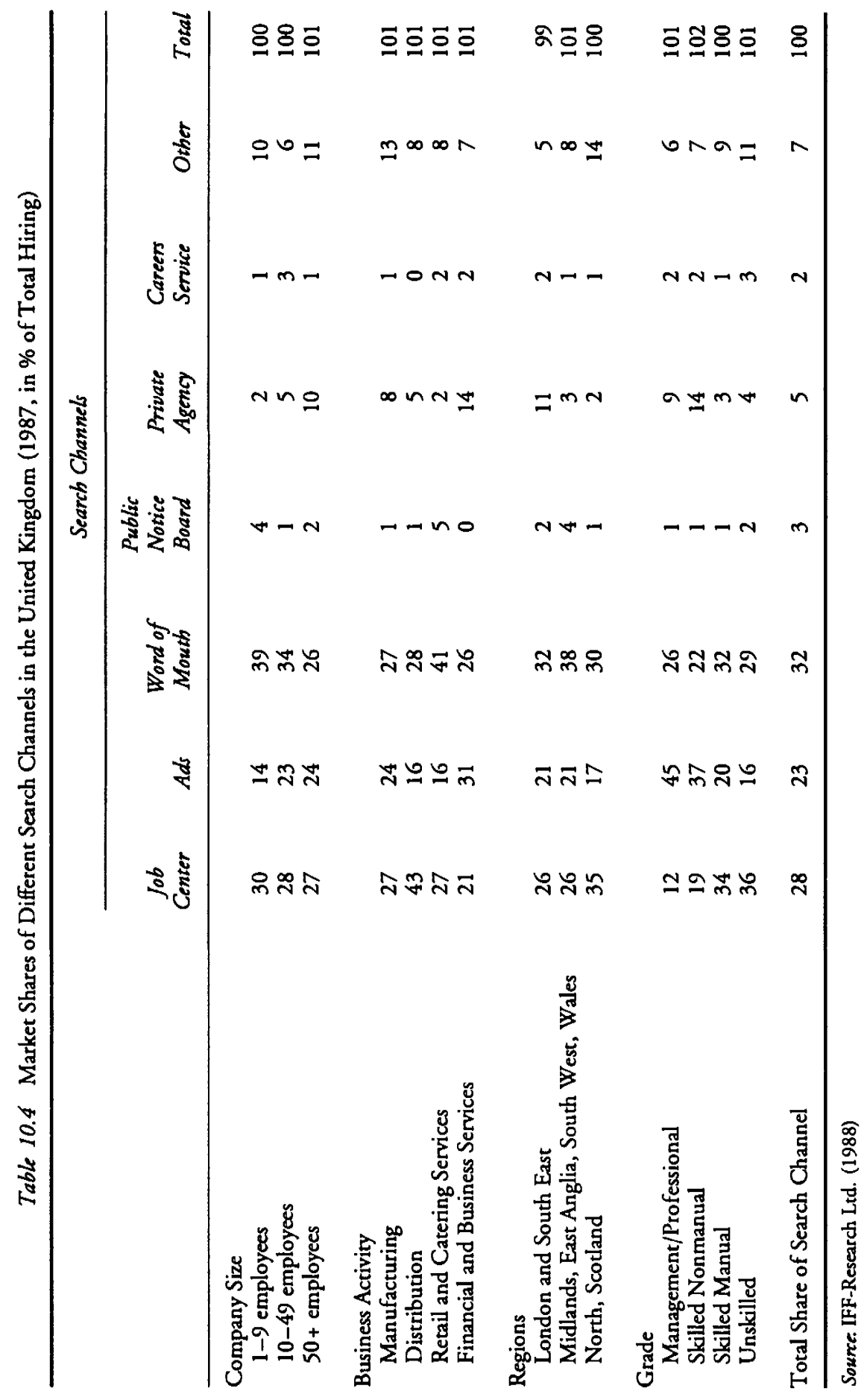


of the market, as experience in the United States clearly shows. Employer disillusionment was particularly damaging. Due to this loss of reputation the PES in the United States even began to lose its ability to serve the disadvantaged (Bishop 1992: 14).

\section{Private Employment Services}

Empirical knowledge for a careful assessment of the activities of private employment services and their possible effects on the labor market is still inadequate. The existing information makes it possible only to give a rough picture about the quantitative importance and structural characteristics of such agencies. This part of the chapter is mainly based on experience with commercial PRES in the United Kingdom but also additional information is given for the Netherlands and the United States (Clark et al. 1989; Smith 1988; FRES 1990; OECD 1993; ILO 1994; Harrison 1992; Stevens 1989).

The number of PRES in the United Kingdom increased greatly in the 1980's. Statistics of the Employment Department show a significant growth of 322 percent in the number of licensed agencies and employment businesses between March 1977 (5,336 license holders) and March 1990 (17,193 license holders). Due to the recession in the United Kingdom it has fallen slightly since then. This recent decline shows that demand for such agencies partly depends on cyclical components. The total number of license holders in 1993 was 14,493-9,506 were licensed as both employment and temporary work agencies, 4,172 were licensed as employment agencies only and 728 were licensed as temporary work agencies only. The market share of PRES is at present assessed at about 5 percent and seems to be clearly below that of the PES (Walwei 1991).

The regional, occupational, and industrial distribution of the employers' use of PRES is illustrated in Table 10.4. Employers were more likely to contact a PRES when recruiting clerical staff or managerial and professional employees. Privatesector employers and those employers with more than 20 employees also contact a private agency more often when recruiting staff.

The number of job seekers who use PRES as their main method of searching for a job also increased from 77,000 in 1984 to 167,000 (4 percent of all job seekers) in 1991, according to the Labour Force Survey. Job seekers using PRES are more likely to

- live in London and the Southeast,

- be without health problems or disabilities,

- be aged between 25 and 50 years,

- have no children,

- be highly qualified,

- be employed,

- have been employed previously,

- have been looking for work for only a short period of time, 
- be employed in managerial and professional or clerical occupations,

- be employed in banking and finance industries,

- have full-time jobs and be seeking full-time employment (Harrison 1992).

About 80 percent of current license holders are small businesses, small being defined as sole trader or single license holder. The majority of PRES do not seem to belong to any representative body. Over 60 percent of license holders are situated in London and the Southeast. However, there being no geographical restrictions on the activities of agencies, there is no part of the United Kingdom without license holders (including, for example, the remote islands of Scotland).

Placement agencies now cover most types of employment, from unskilled work to senior managerial posts. But they specialize in concrete occupational categories. Recruitment to office jobs continues to be one of their major activities. The main growth areas are the upper and lower ends of the labor market. About half the total number of license holders deal in specialist, managerial, and execurive jobs; and nearly one third of them supply domestic and home care workers and au pairs. Demographic change is causing many license holders to draw on groups of potential workers that are currently underused (e.g. older people, women returning to working life).

The placement fee is determined by the market and payable only by the employer. At the moment it is around $12-30$ percent of the annual salary - depending on the qualification requirements for the particular position. In return, commercial agencies take pains to find the most suitable applicant. Their activities are therefore aimed at active acquisition of positions, the careful preparation of requirement profiles, and the conscientious preliminary screening of applicants.

In the Netherlands, the 1990 Employment Service Act permits PRES as intermediaries between jobseekers and recruiting employers. So far, only a limited number of licenses (approximately 800 ) have been issued. Fee-charging employment services normally operate only in segments where highly skilled labor is required. Such agencies account for only 1 percent of all hires into permanent jobs. Of special importance in this context is the role played by the frequently used temporary work agencies. In the Netherlands they can in fact be seen as a substitute for fee-charging employment services. An employer survey shows that transitions from temporary work into a permanent job account for 7 percent of all appointments to permanent jobs (which is not much lower than the 10 percent market share of the PES). Obviously employers in the Netherlands not only use temporary workers to adjust the numerical size of their staff but also to test prospective workers.

Just as in the United Kingdom, in the United States a remarkable growth of the PRES industry has occurred. The increasing importance of private agencies also reflects a prevailing philosophy of the US government that assigns a limited federal role while recognising the predominance of private activities. The number of PRES grew between 1959 and 1993 from 2,500 to 14,000 companies (with a network of 
20,000 offices or branches). Their market share is assessed at about 10 percent, which seems to be significantly higher than that of the PES. According to a survey by the National Association of Personnel Consultants they deal mainly with highly skilled labor. The most commonly covered areas of activity were in 1991, according to the NAPC survey: Clerical (23.1 percent of the total cash in), data processing (15.0 percent), engineering/scientific $(14.2$ percent $)$, and sales/marketing ( 13.6 percent). The respondents report that 96 percent of their placements involve a fee paid by the hiring employer which ranges on average between $\$ 10,324$ (insurance) and $\$ 2,902$ (clerical). Other characteristics such as regional distribution, firm size etc. are very similar to European coexistence countries (NAPC 1992).

There are not many studies dealing with the efficiency of job search or recruiting methods. Two American studies should be mentioned because their results are of special interest in the context of this paper. Bortnick and Harrison-Ports (1992: 29) found that "checking with employers directly" was the search method most often used by unemployed job seekers (approximately 72 percent of the total), but it did not necessarily prove to be the most successful method. Job seekers using a PRES ( 9 percent of all unemployed job seekers) had the highest likelihood of finding employment in 1991. Almost one fourth of them found jobs. However, the results do not suggest that the PRES is the most efficient search method because the authors did not check for certain variables such as qualifications.

Bishop (1992: 12-13) tries to find an answer to the question of why firms pay substantial fees to use a PRES, but he did not find a convincing empirical answer. First, because his data, based on an employer survey, suggest that referrals from PRES were not significantly better than new hires recruited through other channels. Second, because of the fact that the decision process after a referral from a PRES took significantly more hours of staff time than for other informal recruitment sources. One can comment on that result in two ways. On the one hand, employers might be unaware of how poorly they fare with PRES referrals. But on the other hand they might be forced to use them by an absence of other applicants for a hard-to-fill job.

\section{MONOPOLY OR COEXISTENCE: A RELEVANT QUESTION}

The ongoing debate on the liberalization of employment services (especially in European countries) shows several controversies. Proponents of a removal of the monopoly state that the admittance of PRES would have positive effects on the allocation in the labor market and would tend to increase employment and reduce unemployment. They argue that the matching process on the labor market could be made easier by the possibility of using a further search channel. Besides that, private competition is seen as an incentive for public services to improve their own services. The efforts of public employment services toward stabilizing or extending their market share (with the precondition that their existing financial scope is 
retained) would then in turn affect the private competition, and vice versa. Such competition will then reveal and satisfy the various needs of employers and job seekers. On the whole, better placement services from private and public intermediaries would reduce search costs (as argued on page 244) and contribute to placing workers in the job where they can work most productively.

The main counterargument is that PES need a significant share of the placement market to carry out certain public tasks efficiently. A comparatively low market share (due to strong private competition) would

- impede monitoring of the labor market thus enabling the knowledge gained to be turned into necessary measures for individual and general measures in the labor market;

- impede the prevention of abuse of the benefit system. Benefits are generally payable only to those unemployed who are able and willing to take up a reasonable job offer;

- reduce the possibilities for the integration of problem groups through various company contacts and vacancies to be filled. That is because candidates proposed by the PES could be more segmented and stigmatised and filtered - due to the inferior role of the PES and to statistical discrimination.

What could be a possible answer to this controversy regarding the experience from an international comparison in pages 247-257? First of all it has to be said that the existing experience and data in international comparisons are not sufficient. In general, they do not allow a careful assessment of all arguments in the debate. In spite of these serious restrictions the chapter does allow some tentative conclusions to be drawn regarding institutional arrangements for job placement.

First, most vacancies in the economies are filled without the intervention of any kind of employment service. The potential market for job placement is extremely difficult to define. On the one hand, that is because a great deal of recruitment obviously does not require any kind of intermediary. Employer and employee can find each other by chance (informal contact) or perhaps they know each other from previous employment relationships (cf. Deeke 1991). Therefore, the quality and speed of the remaining vacancy fillings are quite independent from the institutional arrangements for job placement. On the other hand, it is difficult to define an optimum economic share of the PES in contrast to the PRES market share that will by and large emerge from market forces. The problem is not only that an optimum economic share is most unlikely to be constant versus time or could be different regarding skills or regions. In addition this is also because of the fact that social costs (in terms of efforts) and benefits (in terms of benefits) of PES activities must not necessarily equal market costs and benefits. Therefore, there is a strong need to evaluate PES placement activities (see below).

Second, there seems to be only little competition between the PES and PRES. In all coexistence countries in the survey, private services can be seen more or less as a complement to the PES. The public sector is still more concerned with the supply side of the labor market; providing placement and guidance to everybody, but 
giving priority to the placing of the unemployed. On the other hand, the private sector mainly targets the demand side, employed job seekers, and the upper end of the labor market. Thus mainly people with relatively low skills and those requiring further training are entrusted to the PES. As the international comparison suggests, this latter observation is also independent of institutional arrangements governing private employment agencies. But further research has to answer the question as to whether such PES/PRES complementarity exists per se or only as a result of coexistence. Longitudinal analyses dealing with market shares in certain labor market segments in countries where recently liberalization took place (e.g. Denmark, Sweden, and Germany) could provide answers.

The finding of PES/PRES complementarity also provides an explanation for the findings in the OECD review report. The market share of the public employment services within their market potential (defined by the complementarity argument) does not as a rule depend on its monopoly status but first of all on its own attractiveness (i.e. the quality of the service). The size of the job placement market is not a fixed quantity. As experience in the United Kingdom shows, the number of placements at the overall economic level might be increased through the possibility of bringing in (more) PRES. Table 10.5 indicates an increase of the market share of public and private employment services together in the UK from 27 percent in 1982 to 33 percent in 1987. During that period the number of private services increased significantly. But as the recent figures for 1992 (joint PES-PRES market share approximately 29 percent) show, the increase was also attributable to the increased difficulties, during a period of economic growth and in a tightening labor market, in filling vacancies through informal methods.

Third, during the second half of the 1980's in many OECD countries, skill shortages were accompanied by considerably high unemployment (mismatch unemployment). It became much more difficult to place unemployed persons in vacant positions compared with the beginning of the 1980's. Indicators were the rightward shift of the Beveridge Curve, the increased duration of vacancies and the growing standard deviation from the average length of a period of unemployment. However, mismatch in the labor market could have a number of reasons-not only the effectiveness of employment services, but also regional, industrial and occupational disparities as well as employers' and job seekers' own efforts in adapting to changing circumstances.

A multiple regression analysis explaining the duration of vacancies and the length of unemployment in western Germany shows that profile discrepancies between unemployed persons and job vacancies hence become more obvious (Buttler and Cramer 1991). The imbalances in the labor market produced a selection process which is typical of a market economy based on competition. The individual firm's decision must always be to recruit the workers that appear the most appropriate for a vacancy. Therefore it is no surprise that the length of unemployment is mainly influenced by factors such as age or health limitations, which may indicate lower individual productive capacity. On the other hand workers are also selective. They are attracted by well-paid jobs that appear to be 
Table 10.5 Market Shares of Different Search Channels in the United Kingdom (1982 and 1987, in $\%$ of total hirings)

\begin{tabular}{lrr}
\hline & 1982 & 1987 \\
\hline Job Center & 24 & 28 \\
Advertisement & 19 & 23 \\
Word of Mouth & 43 & 32 \\
Public Notice Board & 1 & 3 \\
Private Agency & 3 & 5 \\
Careers Service & 3 & 2 \\
Other & 7 & 7 \\
Total & 100 & 100 \\
\hline
\end{tabular}

Sources: Hedges (1983); IFF-Research Ltd. (1988)

secure. The main problem of-private or public-employment services is therefore to match the workers and the jobs that have filtered out of the market.

Assuming another period of economic growth in the near future and then again the appearance of skill shortages, the resulting difficulties will, however, not be solved only by giving more room to the highly specialized private employment services. The efficiency of the public services still plays the key role, because they are mainly responsible for matching those workers and jobs which have filtered out of the market. Because they have all the relevant services for labor market promotion in one organization they are able to give additional aid for integrating unemployed people. In order to support such a policy orientation the following measures to improve the effectiveness of the public employment services are of great importance:

1 PES placement activities have to be evaluated in terms of cost and benefits. The PES market share will not emerge from the market process alone. Because the simple number of placements (e.g. in a given period) reflects neither the effort (in terms of resources) made nor the benefit of each placement. The benefits of PES placements refer to the matching process as such (e.g. with respect to occupational or regional mobility) as well as to the individual needs of employers and employees. PES placement activities affect both sides of the market. From the viewpoint of the individual employer the benefits of placement (compared with other recruitment methods) reflects, for example, e.g. candidates' productivity, required skills or expected turnover. For the individual job seeker, the benefits of placement (compared with other search methods) consist, for example, of the expected job tenure (and the corresponding likelihood of becoming unemployed) and the career. In order to determine the benefits of PES placements, longitudinal analyses (including comparisons with control groups) are required. 
2 Contacts between the PES and small and medium-sized firms should be expanded. Company surveys in western Germany show that the proportion of registered vacancies (related to total vacancies) increases with company size (see Reyher $e t a l .1990$ ). It has to be mentioned that approximately 86 percent of all vacancies are accounted for by small and medium-sized firms (under 200 employees). Another company survey in western Germany shows that disproportionately large numbers of job vacancies with an outstanding duration came from small and medium-sized firms in the hotel and catering sector from trading firms and from construction firms with currently unfavourable sales and employment trends (Cramer 1990). It is reported that a significant proportion of these vacancies were also hard to fill because of disadvantageous locations and working hours. Therefore, it would be important to support the matching of workers and available jobs which have been filtered out of the market by expanding company contacts. This would facilitate a more job-oriented and not predominantly job seeker-oriented placement;

3 The PES could make more use of the matching potential in the labor market. A comprehensive flow of information about vacancies and job seekers between offices is made possible by the use of electronic aids and the implementation of effective self-service systems. With this information on hand the PES could explore more intensively the possibilities for flexibility on the part of the employees and for substitution on the part of the employers. Workers could be encouraged to apply for jobs outside their regular occupational range and employers urged to appoint workers whose qualifications do not exactly fit their requirements but which are more or less equivalent.

4 If a job seeker's own search in the labor market is made easier by the use of more electronic aids as is now the case in many countries, the personnel capacities of the PES could be better concentrated on important tasks and can thus be used more effectively, e.g. for a more active acquisition of vacancies for their mainly unemployed clients by increasing and intensifying contacts with companies (especially small and medium-sized), a more proficient selection of applicants and by putting more emphasis on the beneficial reintegration of the long-term unemployed into the labor market;

5 If private employment agencies are a successful search method even for unemployed job seekers but are nor used very frequently (see Bortnick and Harrison-Ports 1992) one can think about establishing cooperation between the PES and private employment agencies. The U.S. is the only country where a concrete cooperative arrangement already exists. The U.S. employment service is permitted to refer applicants to private agencies as long as they are not charged a fee (i.e. a fee borne by an employer can be charged). In practice this possibility is not used very often. One reason might be the resistance of PES managers to contracting out their original work because this could finally lead to considerable staff cuts. But more important seems to be the PES/PRES complementarity, which limits the scope of cooperation. That means, as Bishop (1992:12) has stated in a general way, "that problems of the employment service cannot be 
solved by contracting out the (placement) function to private employment agencies." Of course, this does not exclude limited areas for cooperation, e.g. bilateral recommendations in order to increase the transparency of the labor market and the matching possibilities. But however, in order to foster the reemployment opportunities for the unemployed it seems to be of special importance to improve the effectiveness of the PES.

\section{REFERENCES}

Akerlof, G. A. (1970) "The Market for Lemons: Quality Uncertainty and the Market Mechanism," Quarterly Journal of Economics 84: 488-500.

Alexander, T. (1992) "Signposts to Success," Paper presented at the Employment Services' Conference on "The Changing Role of Public Employment Services in the 1990's" in Manchester (U.K.), September 30, 1992 to October 2, 1992.

Bortnick, S. M. and Harrison-Ports, M. (1992) "Job Search Methods and Results: Tracking the Unemployed, 1991," Monthly Labor Review 115: 29-35.

Bishop, J. (1992) "Improving Job-Worker Matching in the U.S. Labor Market," Center for Advanced Human Resource Studies, Working Paper 92-40.

Bundesanstalt für Arbeit (1992) "Arbeitsmarkt 1991. Arbeitsmarktanalyse für die alten und die neuen Bundesländer," Nuremberg.

Buttler, F. and Cramer, U. (1991) "Developments and Causes of Mismatch Unemployment in West Germany," in W. Franz (ed.), Structural Unemployment, Heidelberg: PhysicaVerlag.

Caire, G. (1991) "The Intervention of Private Firms in the Functioning of Labor-markets in the Twelve EEC Countries," mimeo, Paris.

Clark, T., Ball, D. and Britton, C. (1989) "The Executive Search and Selection Industry: An Analysis of an Emerging Industry," mimeo, Leicester.

Cramer, U. (1990) "Probleme bei der Besetzung von offenen Stellen. Ergebnisse einer Betriebsbefragung," Mitteilungen aus der Arbeitsmarkt-und Beruffforschung 23: 246-254.

Deeke, A. (1991) Informelle Beziehungen auf dem Arbeitsmarkt. Marktregulierung und Chancenverteilung durch Arbeitsvermittlung, Frankfurt/New York: Campus-Verlag.

FRES (1990) "The Growth of the UK Employment Services Industry," mimeo, London.

Harrison, J. (1991) "Who uses Job Centres," mimeo, Research and Evaluation Branch, Report No. 67, Sheffield.

- (1992) "Private Employment Agencies," mimeo, Research and Evaluation Branch, Report No. 72, Sheffield.

Hedges, B. (1983) "Survey of Employers' Recruitment Practices," mimeo, London.

ILO (1994) "The role of private employment agencies in the functioning of labor markets," Geneva.

Konle-Seidl, R., Ullmann, H. and Walwei, U. (1990) "The European Social Space: Atypical forms of employment and working hours in the European Community," International Social Security Review 43: 151-187.

National Association of Personnel Consultants (1992) "Operational Analysis Survey. Placement Firm Profile Statistics for 1991," mimeo, Washington.

National Commission for Employment Policy (1991) "Improving the Effectiveness of the Employment Service: Defining the Issues," Research Report 91-01, Washington.

OECD (1984) “The Public Employment Service," Paris.

__ (1992) "Employment Outlook," Chapter 3, Paris.

(1993) "The Labour Market in the Netherlands," Paris. 
DIFFERENT INSTITUTIONAL ARRANGEMENTS FOR JOB PLACEMENT

Reyher, L., Spitznagel, E. and Kretschmer, G. (1990) "Das gesamtwirtschaftliche Stellenangebot. Umfang, Struktur und Besetzungsprobleme," Mitteilungen aus der Arbeitsmarkt und Berufsforschung 23: 347-372.

Smith, E. (1988) "Vacancies and Recruitment in Great Britain," Employment Gazette 21: 211-213.

Spence, M. (1973) “Job Market Signaling," Quarterly Journal of Economics 87: 355-376.

Stevens, D. W. (1989) "The Evolution of Public and Private Agency Participation in the Deployment of Human Resources in the United States," mimeo, Washington.

Walwei, U. (1991) "Job Placement in Europe. An International Comparison," Intereconomics 26: 248-254. 